\title{
Solubility and Dissolution Thermodynamic Data of Mefenamic Acid Crystals in Different Classes of Organic Solvents
}

\author{
Siti K. Abdul Mudalip, ${ }^{\dagger \dagger}$ Mohd R. Abu Bakar, ${ }^{*}{ }^{\S}$ Parveen Jamal, ${ }^{\dagger}$ and Fatmawati Adam ${ }^{\ddagger}$ \\ ${ }^{\dagger}$ Department of Biotechnology Engineering, Kulliyyah of Engineering, International Islamic University Malaysia, 50728 Kuala \\ Lumpur, Malaysia

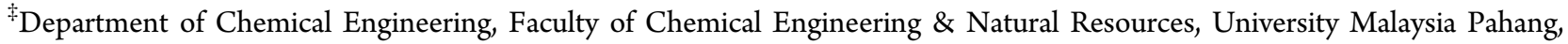 \\ Gambang, 26300 Kuantan, Pahang, Malaysia \\ ${ }^{\S}$ Department of Pharmaceutical Technology, Kulliyyah of Pharmacy, International Islamic University Malaysia, Bandar Indera \\ Mahkota, 25200 Kuantan, Pahang, Malaysia
}

ABSTRACT: Different classes of solvents provide different polarity values, which influence the solubility of pharmaceutical solids. In this article, the solubility of mefenamic acid in different classes of organic solvents, including polar protic, dipolar aprotic, and apolar aprotics at a range of temperatures from (298 to 323 ) $\mathrm{K}$ are reported. It has been found that mefenamic acid shows high solubility in dipolar aprotic solvents ( $N, N$-dimethylacetamide, $N, N$-dimethylformamide, ethyl acetate, and propanone), moderate solubility in polar protic solvents (ethanol and propan-2-ol), and poor solubility in apolar aprotic solvents (hexane, heptane, and cyclohexane) and water.

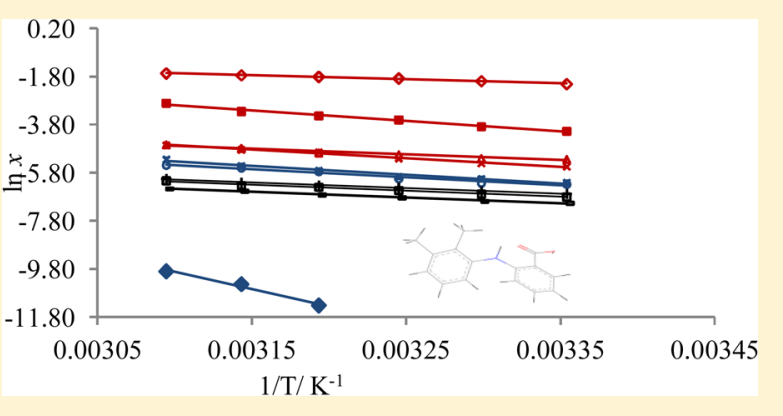

\section{INTRODUCTION}

2-[(2,3-Dimethylphenyl)amino] benzoic acid $\left(\mathrm{C}_{15} \mathrm{H}_{15} \mathrm{NO}_{2}\right.$, mefenamic acid) is a widely used nonsteroidal anti-inflammatory and analgesic agent for the treatment of pain caused by menstrual disorders. ${ }^{1,2}$ The compound has been known to exist in two polymorphic forms: Form I and Form II. $^{1-5}$ An additional polymorph, Form III, has recently been reported. ${ }^{6}$ Form I is relatively stable at ambient conditions as compared to Forms II and III. The order of stability is I > II > III at ambient conditions. However, above $175{ }^{\circ} \mathrm{C}$, the order of stability becomes II $>$ I $>$ III due to the enantiotropic relationship of the polymorphs. ${ }^{6}$ Form II is expected to be more pharmaceutically active than Form I because of its higher solubility. ${ }^{7}$ Although the solubility value for Form III is yet to be reported, it can be inferred that Form III is the most pharmaceutically active due to its lowest value of lattice energy, as compared to Forms I and II. ${ }^{6}$ However, due to the metastable characteristic of Forms II and Form III, the use of Form I in the pharmaceutical formulations is more practical. ${ }^{3,6}$

It has been shown that polymorphs of mefenamic acid can be recrystallized from different solvents. ${ }^{1-6}$ In order to determine the best solvent and suitable crystallization methods for producing different polymorphs of mefenamic acid, it is very important to have the solubility data of the compound in various solvents. ${ }^{8}$ Currently, the availability of such data in the literature is very limited. ${ }^{5,7,9,10}$ The solubility data can be obtained experimentally using a technique known as the isothermal method. ${ }^{11}$ The technique basically involves the determination of a maximum amount of solute that can dissolve in a solvent at a constant temperature with agitation for a time period between 4 to $24 \mathrm{~h}$. The analysis for the solute can be either done gravimetrically ${ }^{12}$ or using spectroscopy. ${ }^{13}$ Some variations of the technique are also available, which are described in detailed elsewhere. ${ }^{11,14}$ Another experimental technique for the solubility determination involves heating up a suspension of solid and solvent to dissolution and detecting the clear point, which is taken as the solubility point, visually or using optical probes. ${ }^{15}$ In the present work, the solubility of mefenamic acid in different classes of organic solvents, which are dipolar aprotic, polar protic, and apolar aprotic are measured using the isothermal method at temperatures ranging from (298 to 323) $\mathrm{K}$. The solvents are $N, N$-dimethylacetamide (DMA), N,N-dimethylformamide (DMF), ethyl acetate (EA) and propanone, ethanol, propan-2-ol (IPA), hexane, heptane, cyclohexane, and water. The solubility data of mefenamic acid in ethyl acetate obtained in this work are compared with the literature. ${ }^{5,7}$ The enthalpy of dissolution and Gibbs free energy are computed from the experimental data using the modified van't Hoff equation.

\section{EXPERIMENTAL SECTION}

Materials. Table 1 shows the description of materials used in this work. Results of powder X-ray diffraction (PXRD) analysis for mefenamic acid illustrated in Figure 1 show that the received mefenamic acid is Form I. The characteristics of solvents, such as dielectric constant $(\varepsilon)$, molecule dipole moment $(D M)$, polarity index $(P I)$, cohesive energy density $(E)$, summation of hydrogen donor propensity $\left(\sum H_{\mathrm{d}}\right)$, and summation of hydrogen acceptor propensity $\left(\sum H_{\mathrm{a}}\right)$ are shown in Table 2 .

Received: August 5, 2013

Accepted: November 6, 2013

Published: November 21, 2013 
Table 1. Description of Materials Used

\begin{tabular}{|c|c|c|c|c|}
\hline $\begin{array}{l}\text { chemical } \\
\text { name }\end{array}$ & source & $\begin{array}{l}\text { initial mass } \\
\text { fraction } \\
\text { purity }\end{array}$ & $\begin{array}{l}\text { purification } \\
\text { method }\end{array}$ & $\begin{array}{l}\text { analysis } \\
\text { method }\end{array}$ \\
\hline $\begin{array}{l}\text { mefenamic } \\
\text { acid }\end{array}$ & $\begin{array}{l}\text { Baoji Tianxin } \\
\text { Pharmaceutical } \\
\text { Co. Ltd., China }\end{array}$ & 0.9800 & none & $\mathrm{HPLC}^{a}$ \\
\hline ethanol & Fisher Scientific & 0.9990 & none & $\mathrm{GC}^{b}$ \\
\hline propan-2-ol & Fisher Scientific & 0.9999 & none & $\mathrm{GC}^{b}$ \\
\hline $\begin{array}{l}N, N \text {-dimethyl } \\
\text { acetamide }\end{array}$ & Fisher Scientific & 0.9900 & none & $\mathrm{GC}^{b}$ \\
\hline $\begin{array}{l}N, N \text {-dimethyl } \\
\text { formamide }\end{array}$ & Fisher Scientific & 0.9900 & none & $\mathrm{GC}^{b}$ \\
\hline propanone & Fisher Scientific & 0.9950 & none & $\mathrm{GC}^{b}$ \\
\hline ethyl acetate & Fisher Scientific & 0.9950 & none & $\mathrm{GC}^{b}$ \\
\hline hexane & Fisher Scientific & 0.9990 & none & $\mathrm{GC}^{b}$ \\
\hline heptane & Fisher Scientific & 0.9900 & none & $\mathrm{GC}^{b}$ \\
\hline cyclohexane & Fisher Scientific & 0.9900 & none & $\mathrm{GC}^{b}$ \\
\hline
\end{tabular}

Solubility Measurement. The isothermal method ${ }^{11}$ was used to determine the solubility of mefenamic acid in various solvents listed in Table 2. An excess of mefenamic acid was added into glass vials containing two (2) $\mathrm{mL}$ of solvent and shaken in a temperature controlled block (Eppendorf Thermomixer Shaker) at a range of temperatures between (298 and 323) K. All samples were maintained at the selected temperatures for a period of $24 \mathrm{~h}$ to reach equilibrium. After that, the supernatant solutions were separated at isothermal conditions by filtration using a $0.45 \mu \mathrm{m}$ PTFE membrane syringe filter. The supernatant was transferred into an evaporating dish, which was initially weighed to determine its empty weight. After the transfer, the evaporating dish was weighed again to determine the wet weight.

Assay of the supernatants was conducted using the gravimetric method ${ }^{12}$ that involves evaporation overnight, i.e., approximately a few hours at room temperature initially and then increased to $60{ }^{\circ} \mathrm{C}$. The evaporating dish was repeatedly weighed and dried until constant weights were obtained (dry weight). The information on dry, wet, and empty weights was used to calculate the solubility of the solute in the solvent and construct the solubility curve. All of the experimental results were the average of three replicated experiments. The solubility,
$S$ of solute in the solvents at a particular temperature was calculated as follows:

$$
S=\frac{w_{\mathrm{d}}-w_{\mathrm{o}}}{w_{\mathrm{w}}-w_{\mathrm{d}}}
$$

where $w_{\mathrm{o}}$ is the empty weight, $w_{\mathrm{w}}$ is the wet weight, $w_{\mathrm{d}}$ is the dry weight, and $w_{\mathrm{d}}-w_{\mathrm{o}}$ is the weight of the solute. In eq $2, m_{1}$ is in grams, while $w_{\mathrm{w}}-w_{\mathrm{d}}$ is the weight of solvent, and $m_{2}$ is in grams. An average value was used to calculate the mole fraction solubility, $x_{1}$ based on the following equation:

$$
x_{1}=\frac{m_{1} / M_{1}}{m_{1} / M_{1}+m_{2} / M_{2}}
$$

where $M_{1}$ and $M_{2}$ are the molecular weights of the solute and the solvent, respectively. ${ }^{16}$

\section{RESULTS AND DISCUSSION}

Solubility. The solubilities of mefenamic acid in ethanol, IPA, water, DMA, DMF, EA, propanone, hexane, heptane, and cyclohexane in mole fraction measured from (298 to 323) K with their uncertainties are tabulated in Table 3. On the basis of the extensive literature review, this is the first time the solubility data of mefenamic acid in hexane, heptane, and cyclohexane have been reported. These solubility data are used to construct linearized van't Hoff plots as presented in Figure 2. The $R^{2}$ values of the van't Hoff plots are between 0.97 and 0.99 and thus signify the reliability of the experimental solubility data. The result on the solubility of mefenamic acid in EA obtained in this work was compared with those in the literature and are shown in Figure 3. As can be seen, the data show a satisfactory agreement with that of Park and co-workers. ${ }^{7}$ The solubility data in this work deviate less than $10 \%$ with those in the literature as shown in Table 4 . The solubility value of mefenamic acid in ethanol and ethyl acetate at $298 \mathrm{~K}$ were reported by Romero et $\mathrm{al}^{5}{ }^{5}$ in mole fractions as 0.0018 and 0.0038 , respectively. These values only deviates less than $5 \%$ than those reported in this work, which was 0.0019 and $0.0039 \mathrm{~mol}$ fractions in ethanol and ethyl acetate, respectively.

The chemical structure of mefenamic acid, which consists of carboxylic, amine, aromatic, and methyl groups, is shown in Figure 4. The presence of carboxylic and amine group in its chemical structure demonstrates polar protic characteristics,

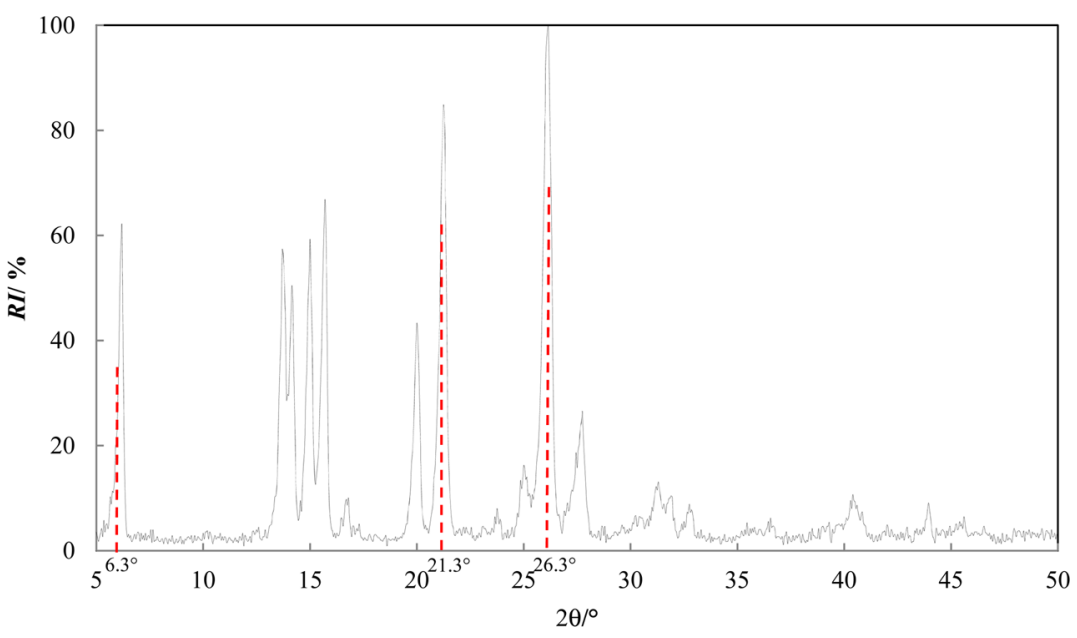

Figure 1. Comparison of PXRD patterns of mefenamic acid powder (raw material) in this work with that of major peaks obtained by Kato and co-workers. ${ }^{3}$ Solid line, this work; and dashed line, Kato and co-workers. ${ }^{3}$ RI stands for relative intensities. 
Table 2. Characteristics of Polar Protic, Dipolar Aprotic and Apolar Aprotic Solvents ${ }^{a}$

\begin{tabular}{|c|c|c|c|c|c|c|}
\hline solvents & $\varepsilon^{18}$ & $D M^{19}$ & $P I^{18}$ & $E^{20}$ & $\sum H_{d}^{21,22}$ & $\sum H_{\mathrm{a}}^{21,22}$ \\
\hline \multicolumn{7}{|c|}{ Polar Protic } \\
\hline ethanol & 24.55 & 1.69 & 5.01 & 618.87 & 0.37 & 0.48 \\
\hline IPA & 19.92 & 1.56 & 4.57 & 489.11 & 0.33 & 0.56 \\
\hline water & $78.36^{23}$ & 1.87 & 10.2 & 2095.93 & 1.17 & 0.47 \\
\hline \multicolumn{7}{|c|}{ Dipolar Aprotic } \\
\hline DMA & 37.78 & 3.70 & 5.21 & 439.94 & & 0.78 \\
\hline DMF & 36.71 & 3.82 & 5.34 & 463.96 & & 0.74 \\
\hline propanone & 20.70 & 2.88 & 4.61 & 362.07 & 0.04 & 0.49 \\
\hline EA & 6.70 & 1.78 & 4.17 & 300.64 & & 0.45 \\
\hline \multicolumn{7}{|c|}{ Apolar Aprotic } \\
\hline hexane & 1.88 & 0.00 & 0.35 & 200.76 & & \\
\hline heptane & 1.92 & 0.00 & 0.39 & 200.08 & & \\
\hline cyclohexane & 2.00 & 0.00 & 1.02 & 254.59 & & \\
\hline
\end{tabular}

${ }^{a} \varepsilon$ is the dielectric constant; $D M$ is the molecule dipole moment; $P I$ is the polarity index; $E$ is the cohesive energy density; $\sum H_{\mathrm{d}}$ is the summation of hydrogen donor propensity; and $\sum H_{\mathrm{a}}$ is the summation of hydrogen acceptor propensity.

Table 3. Saturated Mole Fraction Solubility $x$ of Mefenamic Acid in Different Organic Solvents at Experimental Pressure (0.1 MPa) and Temperatures $T$ from $(298$ to 323$) \mathrm{K}^{a}$

\begin{tabular}{|c|c|c|c|c|c|}
\hline \multirow[b]{3}{*}{ solvent } & $T$ & $x$ & & $T$ & $x$ \\
\hline & $\mathrm{K}$ & & & $\mathrm{K}$ & \\
\hline & \multicolumn{5}{|c|}{ solvent } \\
\hline \multirow[t]{6}{*}{ ethanol } & 298 & 0.0019 & \multirow[t]{6}{*}{ IPA } & 298 & 0.0020 \\
\hline & 303 & 0.0020 & & 303 & 0.0024 \\
\hline & 308 & 0.0024 & & 308 & 0.0026 \\
\hline & 313 & 0.0032 & & 313 & 0.0033 \\
\hline & 318 & 0.0037 & & 318 & 0.0040 \\
\hline & 323 & 0.0042 & & 323 & 0.0053 \\
\hline \multirow[t]{6}{*}{ water } & 298 & 0.0000 & \multirow[t]{6}{*}{ DMA } & 298 & 0.1219 \\
\hline & 303 & 0.0000 & & 303 & 0.1377 \\
\hline & 308 & 0.0000 & & 308 & 0.1535 \\
\hline & 313 & 0.00001 & & 313 & 0.1648 \\
\hline & 318 & 0.00003 & & 318 & 0.1753 \\
\hline & 323 & 0.00005 & & 323 & 0.1901 \\
\hline \multirow[t]{6}{*}{ DMF } & 298 & 0.0171 & \multirow[t]{6}{*}{ EA } & 298 & 0.0039 \\
\hline & 303 & 0.0208 & & 303 & 0.0045 \\
\hline & 308 & 0.0275 & & 308 & 0.0055 \\
\hline & 313 & 0.0327 & & 313 & 0.0071 \\
\hline & 318 & 0.0391 & & 318 & 0.0079 \\
\hline & 323 & 0.0551 & & 323 & 0.0096 \\
\hline \multirow[t]{6}{*}{ propanone } & 298 & 0.0054 & \multirow[t]{6}{*}{ hexane } & 298 & 0.0013 \\
\hline & 303 & 0.0055 & & 303 & 0.0014 \\
\hline & 308 & 0.0065 & & 308 & 0.0016 \\
\hline & 313 & 0.0070 & & 313 & 0.0018 \\
\hline & 318 & 0.0084 & & 318 & 0.0020 \\
\hline & 323 & 0.0098 & & 323 & 0.0024 \\
\hline \multirow[t]{6}{*}{ heptane } & 298 & 0.0011 & \multirow[t]{6}{*}{ cyclohexane } & 298 & 0.0009 \\
\hline & 303 & 0.0013 & & 303 & 0.0009 \\
\hline & 308 & 0.0015 & & 308 & 0.0011 \\
\hline & 313 & 0.0017 & & 313 & 0.0012 \\
\hline & 318 & 0.0018 & & 318 & 0.0014 \\
\hline & 323 & 0.0022 & & 323 & 0.0016 \\
\hline
\end{tabular}

${ }^{a}$ The standard uncertainty $u$ is $u(T)=1 \mathrm{~K}$; the relative standard uncertainty, $u_{r}(x)=0.05$.

while the aromatic and methyl groups are nonpolar. During the dissolution process, the carboxylic group of mefenamic acid, which is more electronegative than the amine group, will donate a hydrogen atom and form a hydrogen bond with either
Table 4. Deviation $D$ of Experimental Mefenamic Acid Solubility $S$ in Ethyl Acetate at Various Temperatures from Literature Data

\begin{tabular}{|c|c|c|c|}
\hline$T$ & $S_{\text {Experimental }}$ & $S_{\text {Literature }}{ }^{7}$ & $D^{a}$ \\
\hline $\mathrm{K}$ & $100 w$ & $100 w$ & \\
\hline 298 & 1.0664 & 1.00 & 6.64 \\
\hline 303 & 1.2294 & 1.18 & 4.63 \\
\hline 308 & 1.4948 & 1.45 & 3.09 \\
\hline 313 & 1.9316 & 1.80 & 7.31 \\
\hline 318 & 2.1391 & 2.20 & 2.77 \\
\hline 323 & 2.6257 & 2.70 & 2.75 \\
\hline
\end{tabular}

Table 5. Calculated Dissolution Enthalpy $\Delta H_{\text {diss }}$ and Gibbs Free Energy Change $\Delta G_{\text {diss }}$ of Mefenamic Acid in Various Solvents

\begin{tabular}{|c|c|c|c|c|c|}
\hline \multirow[b]{3}{*}{ solvent } & $\Delta H_{\text {diss }}$ & $\begin{array}{c}\Delta G_{\text {diss }} \text { at } \\
298 \mathrm{~K}\end{array}$ & $\begin{array}{c}\Delta G_{\text {diss }} \text { at } \\
308 \mathrm{~K}\end{array}$ & $\begin{array}{c}\Delta G_{\text {diss }} \text { at } \\
318 \mathrm{~K}\end{array}$ & $\begin{array}{c}\Delta G_{\text {diss }} \text { at } \\
328 \mathrm{~K}\end{array}$ \\
\hline & $\mathrm{kJ} \cdot \mathrm{mol}^{-1}$ & $\mathrm{~kJ} \cdot \mathrm{mol}^{-1}$ & $\mathrm{~kJ} \cdot \mathrm{mol}^{-1}$ & $\mathrm{~kJ} \cdot \mathrm{mol}^{-1}$ & $\mathrm{~kJ} \cdot \mathrm{mol}^{-1}$ \\
\hline & & & & & \\
\hline ethanol & 27.9025 & 15.49 & 15.08 & 14.66 & 14.45 \\
\hline IPA & 30.3718 & 15.53 & 15.03 & 14.53 & 14.28 \\
\hline water & 119.0427 & 33.64 & 30.77 & 27.91 & 26.47 \\
\hline DMA & 13.8515 & 5.16 & 4.87 & 4.58 & 4.44 \\
\hline DMF & 36.1335 & 10.17 & 9.30 & 8.43 & 7.99 \\
\hline EA & 29.3541 & 13.80 & 13.28 & 12.75 & 12.49 \\
\hline propanone & 18.2663 & 13.13 & 12.96 & 12.78 & 12.70 \\
\hline hexane & 19.3555 & 16.56 & 16.47 & 16.37 & 16.33 \\
\hline heptane & 21.0266 & 16.87 & 16.73 & 16.59 & 16.52 \\
\hline cyclohexane & 20.0705 & 17.55 & 17.47 & 17.38 & 17.34 \\
\hline
\end{tabular}

polar or dipolar aprotic solvents in the solution. Prior to the formation of the hydrogen bond between mefenamic acid molecules and solvents, the solvent-solvent interactions in the solution need to be broken. As shown in Figure 2, the solubilities of mefenamic acid are high in dipolar aprotic solvents studied in the order of DMA, DMF, propanone, EA. However, the solubilities are moderate in polar protic solvents, which are IPA and ethanol. The solubilities are low in the apolar aprotic solvents studied, which are hexane, heptane, and cyclohexane. Although water is a polar protic solute, mefenamic acid shows very low solubility in it. In terms of the temperature 


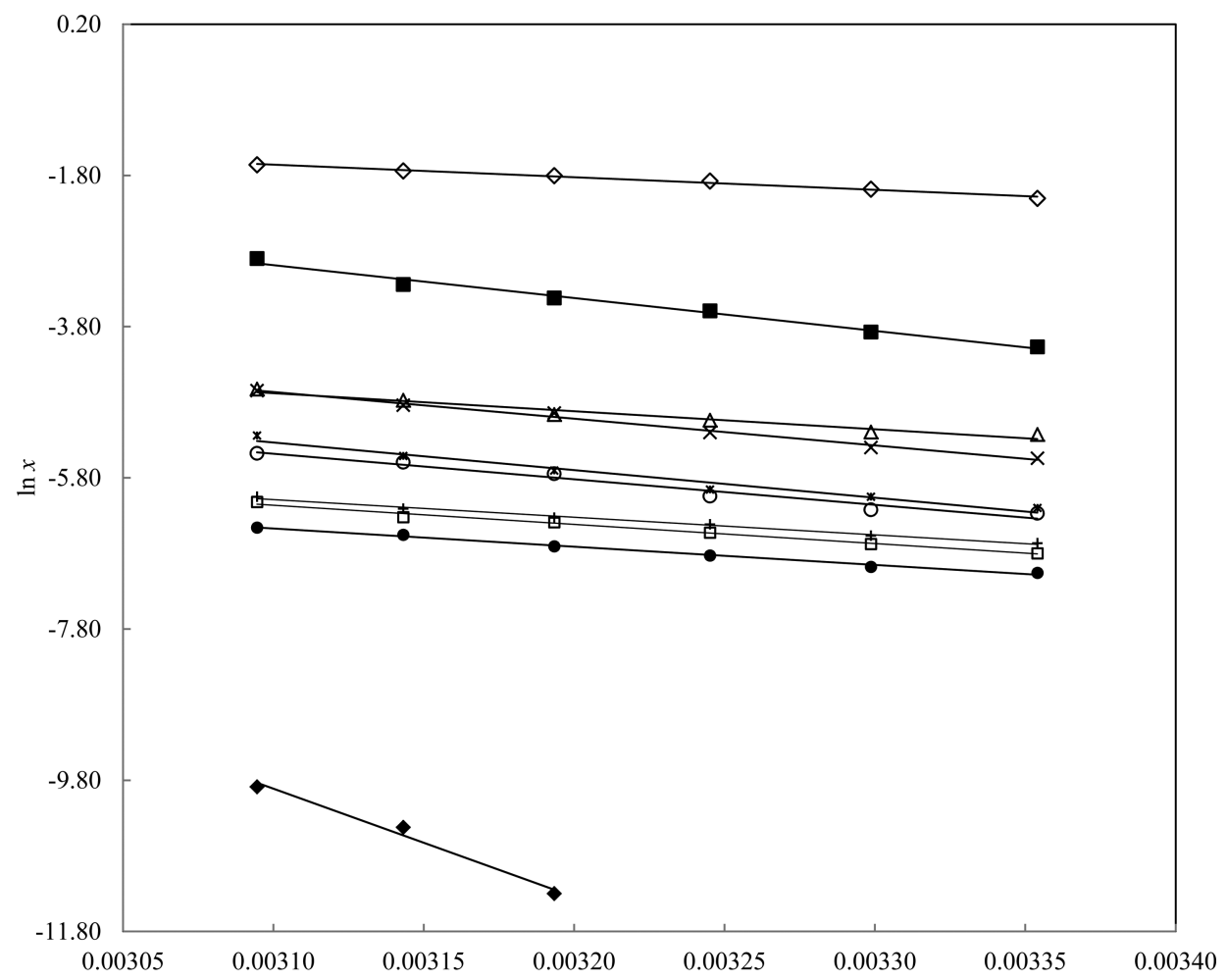

$1 / T / \mathrm{K}^{-1}$

Figure 2. van't Hoff plot of the saturated mole fraction solubility of mefenamic acid $x$ and reciprocal temperature in different organic solvents: $\diamond$, DMA; $\mathbf{\square}$, DMF; $\Delta$, propanone; $\times$, ethyl acetate; *, IPA; $o$, ethanol; +, hexane; $\square$, heptane; $\bullet$, cyclohexane; $\bullet$, water.

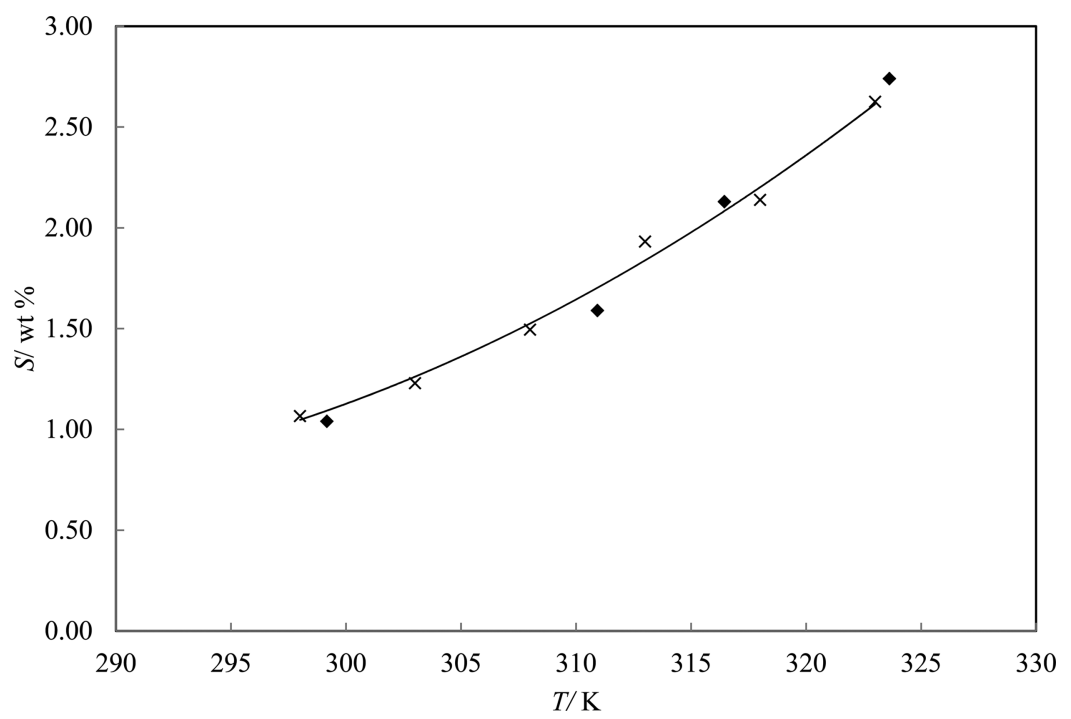

Figure 3. Comparison of mass fraction solubility data $S$ of mefenamic acid in ethyl acetate at different temperatures obtained in this work $(\times)$ and in the work by Park and co-workers $(\diamond)$ ?

effect, the solubility of mefenamic acid is increased with the increase of temperature for all of the solvents studied. These findings are in agreement with Mullin. ${ }^{17}$

It is widely known that the protic solute is more soluble in dipolar aprotic solvents followed by polar protic and apolar aprotic solvents. ${ }^{17}$ This is probably due to the formation of the higher strength of the hydrogen bonds between the protic solute and the dipolar aprotic solvents during the dissolution process compared to that in polar protic solvents. In apolar aprotic solvents, no hydrogen bonds are formed. The low solubility values in apolar aprotic solvents might be due to the weak van der Waals interaction between the molecules. In water, the protic atoms of mefenamic acid, which are $\mathrm{COO}^{-}$and $\mathrm{N}^{+}$, have a tendency to provide hydrogen atoms to water molecules and may form hydrogen bonds with water. However, the presence of aromatic and methyl groups in the mefenamic acid chemical structure is more dominant and influences the structure of the surrounding water molecules and thus leads to poor solubility. 


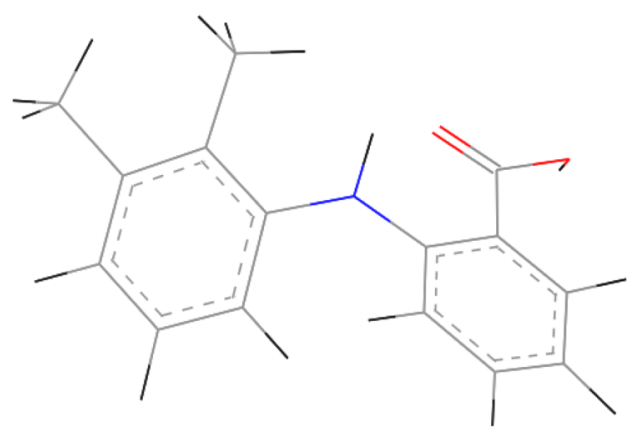

Figure 4. Chemical structure of mefenamic acid Form I. Color representation: gray, carbon; black, hydrogen; blue, nitrogen; and red, oxygen.

Heat of Dissolution and Gibbs Free Energy Change. Heat of dissolution and Gibbs free energy change during the dissolution process are important parameters, which are associated with the solubility behavior of the targeted compound. The higher energy changes during the dissolution process indicate high stability in solid phase and lower solubility values. ${ }^{24}$ Using the linear fitting of the van't Hoff plot in Figure 2, the dissolution enthalpy and entropy in respective solvents were determined. The value of enthalpy of dissolution, $\Delta H_{\text {diss }}$ in $\mathrm{J} \cdot \mathrm{mol}^{-1}$, calculated from the graph's slope in Figure 2, indicated the amount of heat adsorbed or released during disaggregation and diffusion of mefenamic acid in each solvent used. The entropy of dissolution, $\Delta S_{\text {diss }}$ in $\mathrm{J} \cdot(\mathrm{mol} \cdot \mathrm{K})^{-1}$ obtained from the $y$-intercept describes the disorder of the dissolution process. The relationsip between $\Delta H_{\text {diss }}$ and $\Delta S_{\text {diss }}$ with the changes of Gibbs free energy, $\Delta G_{\text {diss }}$ in different solvents is shown by the GibbsHelmholtz equation: ${ }^{25}$

$$
\Delta G_{\text {diss }}=\Delta H_{\text {diss }}-T \Delta S_{\text {diss }}
$$

The calculated values of heat of dissolution, $\Delta H_{\text {diss }}$, and change in Gibbs free energy are tabulated in Table 5. From this table, it is clear that the values of $\Delta H_{\text {diss }}$ and $\Delta G_{\text {diss }}$ are positive in all solvents studied. These values indicate that the dissolution process of mefenamic acid in the solvents is endothermic but not a spontaneous process. The highest values of $\Delta H_{\text {diss }}$ and $\Delta G_{\text {diss }}$ were obtained during the dissolution of mefenamic acid in water, which indicates low solubility or poor solute-solvent interactions. However, the values of $\Delta H_{\text {diss }}$ and $\Delta G_{\text {diss }}$ were the lowest ones in DMA, which indicate high solubility or good solute-solvent interactions.

The plot of Gibbs free energy change $\left(\Delta G_{\text {diss }}\right)$ studied for each solvent as a function of temperature is shown in Figure 5. The decrease of $\Delta G_{\text {diss }}$ values with the decrease in the solution temperature indicates less energy is required to initiate the dissolution of mefenamic acid in the respective solvents. Therefore, high solubility or good solute-solvent interactions are obtained at higher temperature.

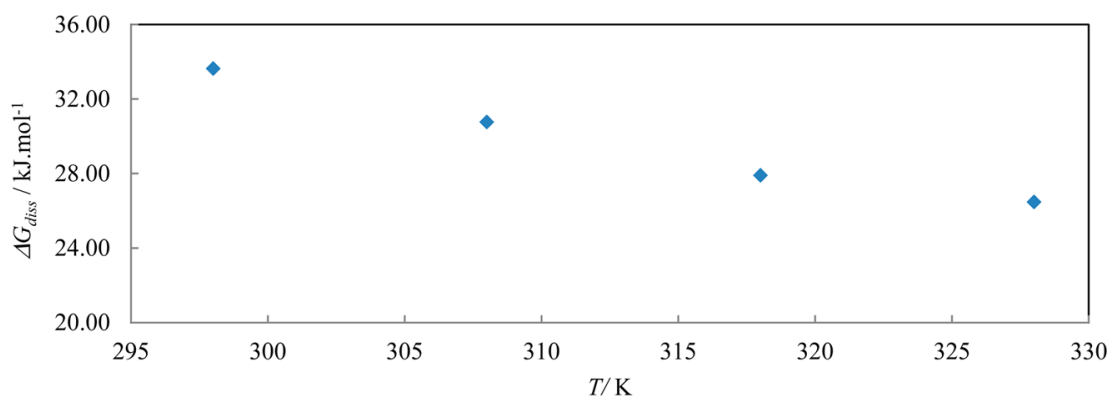

(a)

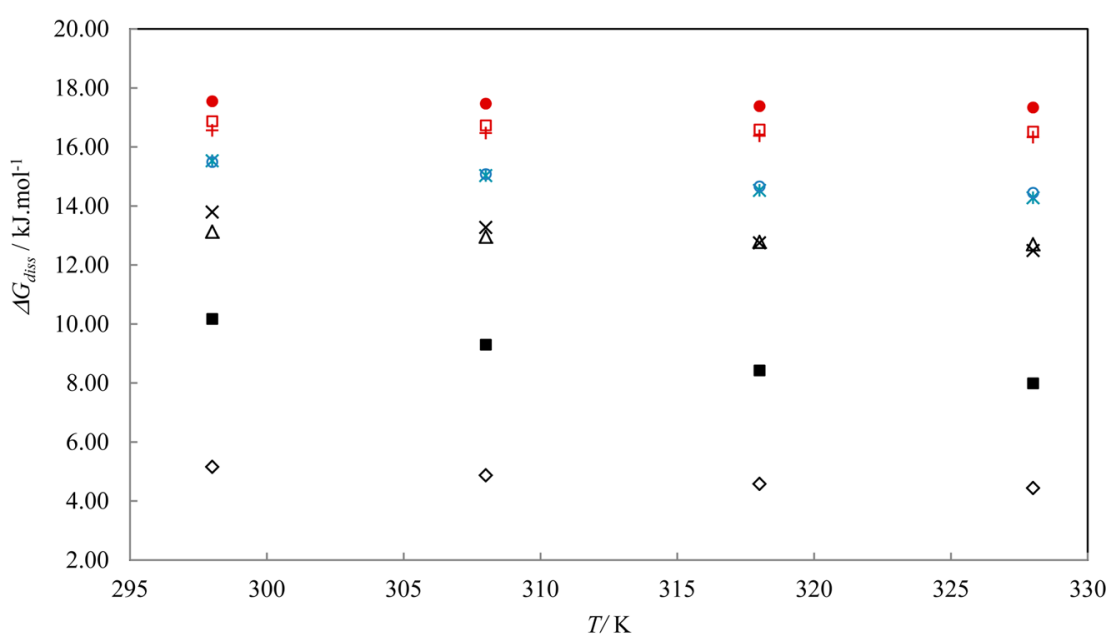

(b)

Figure 5. Gibbs free energy change of dissolution $\Delta G_{\text {diss }}$ as a function of temperature $T$ in (a) water and (b) organic solvents: $\diamond, D M A ; \mathbf{\square}, D M F ; \Delta$, propanone; $X$, ethyl acetate; blue asterisk, IPA; blue circle, ethanol; red +, hexane; red open square, heptane; and red circle, cyclohexane. Color representation: black, dipolar aprotic solvents; blue, polar protic solvents; and red, apolar aprotic solvents. 


\section{CONCLUSIONS}

The solubility of mefenamic acid in three different classes of organic solvents from (298 to 323 ) $\mathrm{K}$ was determined using isothermal and gravimetric methods. It was found that the solubility values increased with temperatures for all of the solvents tested in this work. Mefenamic acid demonstrates high solubility values in the dipolar aprotic solvents studied in the order of DMA, DMF, propanone, and EA, followed by polar protic solvents, which are IPA and ethanol. The solubilities are low in the apolar aprotic solvents studied, which are hexane, heptane, and cyclohexane. Water, which is a polar protic solvent, however, is not a suitable solvent for the dissolution of mefenamic acid. Different hydrogen bonding propensities in the solvents have contributed to different solubility values. The calculated values of enthalpy and Gibbs free energy change of dissolution of mefenamic acid in solvents are consistent with the experimental solubility data.

\section{AUTHOR INFORMATION}

\section{Corresponding Author}

*Tel: +6-09-5704846. Fax: +6-09-5716775. E-mail: rushdi@ iium.edu.my.

\section{Funding}

The work was financially supported by the International Islamic University Malaysia (Endownment Fund B12-363-0841) and the Universiti Malaysia Pahang (RDU110380).

\section{Notes}

The authors declare no competing financial interest.

\section{ACKNOWLEDGMENTS}

S.K.A.M. is grateful to the Malaysian Ministry of Higher Education and the Universiti Malaysia Pahang for a scholarship.

\section{REFERENCES}

(1) Panchagnula, R.; Sundaramurthy, R.; Pillai, O.; Agrawal, S. SolidState Characterization of Mefenamic Acid. J. Pharm. Sci. 2004, 93, 1019-1029.

(2) Cesur, S.; Gokbel, S. Crystallization of Mefenamic Acid and Polymorphs. Cryst. Res. Technol. 2008, 43, 720-728.

(3) Kato, F.; Otsuka, M.; Matsuda, Y. Kinetic Study of the Transformation of Mefenamic Acid Polymorphs in Various Solvents and Under High Humidity Conditions. Int. J. Pharm. 2006, 321, 1826.

(4) Otsuka, M.; Kato, F.; Matsuda, Y. Effect of Temperature and Kneading Solution on Polymorphic Transformation of Mefenamic Acid during Granulation. Solid State Ionics 2004, 172, 451-453.

(5) Romero, S.; Escalera, B.; Bustamante, P. Solubility Behavior of Polymorphs I and II of Mefenamic Acid in Solvent Mixtures. Int. J. Pharm. 1999, 178, 193-202.

(6) SeethaLekshmi, S.; Guru Row, T. N. Conformational Polymorphism in a Non-steroidal Anti-inflamatory Drug, Mefenamic Acid. Cryst. Growth Des. 2012, 12, 4283-4289.

(7) Park, K.; Evans, J. M. B.; Myerson, A. S. Determination of Solubility of Polymorphs Using Differential Scanning Calorimetry. Cryst. Growth Des. 2003, 3, 991-995.

(8) Abu Bakar, M. R.; Nagy, Z. K.; Dann, S. E.; Rielly, C. D. Investigation of the Riddle of Sulfathiazole Polymorphism. Int. J. Pharm. 2011, 414, 86-103.

(9) Hezave, A. Z.; Khademi, M. H.; Esmaeilzadeh, F. Measurement and Modeling of Mefenamic Acid Solubility in Supercritical Carbon Dioxide. Fluid Phase Equilib. 2012, 313, 140-147.

(10) Domanńska, U.; Pobudkowska, A.; Pelczarsk, A. Solubility of Sparingly Soluble Drug Derivatives of Anthranilic Acid. J. Phys. Chem. B 2011, 115, 2547-2554.
(11) Myerson, A. S. Handbook of Industrial Crystallization; Butterworth-Heinemann, Ltd.: Oxford, U.K., 2002.

(12) Abu Bakar, M. R.; Nagy, Z. K.; Saleemi, A. N.; Rielly, C. D. The Impact of Direct Nucleation Control on Crystal Size Distribution in Pharmaceutical Crystallization Processes. Cryst. Growth Des. 2009, 9, $1378-1384$.

(13) Fujiwara, M.; Chow, P. S.; Ma, D. L.; Braatz, R. D. Paracetamol Crystallisation Using Laser Backscattering and ATR-FTIR Spectroscopy: Metastability, Agglomeration and Control. Cryst. Growth Des. 2002, 2, 363-370.

(14) Alvarez, A. J.; Singh, A.; Myerson, A. S. Polymorph Screening: Comparing a Semi-Automated Approach with a High Throughput Method. Cryst. Growth Des. 2009, 9, 4181-4188.

(15) Barrett, P.; Glennon, B. Characterizing the Metastable Zone Width and Solubility Curve Using Lasentec FBRM and PVM. Trans IChemE Part A 2002, 80, 799-805.

(16) Chen, Z.; Xie, C.; Xu, Z.; Wang, Y.; Zhao, H.; Hao, H. Determination and Correlation of Solubility Data and Dissolution Thermodynamic Data of L-Lactide in Different Pure Solvents. J. Chem. Eng. Data 2013, 58, 143-150.

(17) Mullin, J. W. Crystallization, 4th ed.; Butterworth-Heinemann: Oxford, U.K., 2001.

(18) Rohani, S.; Horne, S.; Murthy, K. Control of Product Quality in Batch Crystallization of Pharmaceuticals and Fine Chemicals, Part 1: Design of the Crystallization Process and the Effect of Solvent. Org. Process Res. Dev. 2005, 9, 858-872.

(19) Lide, D. R. Handbook of Organic Solvents; CRC Press: Boca Raton, FL, 1995.

(20) Gu, C.-H.; Li, H.; Gandhi, R. B.; Raghavan, K. Grouping Solvents by Statistical Analysis of Solvent Property Parameters: Implication to Polymorph Screening. Int. J. Pharm. 2004, 283, 117125.

(21) Abraham, M. H. Hydrogen Bonding. Part 31. Construction of Scale of Solute Effective or Summation Hydrogen Bond Basicity. J. Phys. Org. Chem. 1993, 6, 660-684.

(22) Abraham, M. H. Physico-chemical and Biological Processes. Chem. Soc. Rev. 1993, 73-83.

(23) Miller, J. M.; Rodriguez-Hornedo, N.; Blackburn, A. C.; Macikenas, D.; Collman, B. M. In Solvent Systems and Their Selection in Pharmaceutics and Biopharmaceutics; Augustijns, P.; Brewster, M. E., Eds.; Springer: New York, 2007; pp 53-109.

(24) Gracin, S.; Rasmuson, A. C. Solubility of Phenylacetic Acid, pHydroxybenzoic Acid, and Ibuprofen in Pure Solvents. J. Chem. Eng. Data 2002, 47, 1379-1383.

(25) Garcia-Delgado, R. A.; Cotoruelo-Minguez, L. M.; Rodriguez, J. J. Equilibrium Study of Single-Solute Adsorption of Anionic Surfactants with Polymeric Xad Resins. Sep. Sci. Technol. 1992, 27, 975-987. 